\title{
PRESIDENTIAL ADDRESS TO THE 53RD NEW ZEALAND PLANT PROTECTION CONFERENCE ON 9 AUGUST 2000
}

\author{
D.M. SUCKLING
}

\section{The Plant Protection Environment}

This year has seen some dramatic events on the world stage. The season began with another La Niña, and with what we are increasingly learning to expect, extremes of weather have occurred throughout the Pacific and right across to Europe. In New Zealand this increasing unpredictability is certain to be accompanied by an increase in the status of significant plant protection problems - some pests, diseases and weeds which are normally at the end of their climatic range will proliferate. The challenge we will increasingly face will be to remain vigilant, and expect to deal with a wider range of problems than seen previously, as warmer temperatures and changing rainfall patterns offer expanded ranges for pests, apart from the increased rate of incursions of new species.

Restructuring of government-funded science this year has yet again brought changes in the pressures on plant protection sciences. Surprisingly, the focus has shifted away from sustainable production, towards other areas, including human health and wellness, and new plant varieties. This increasing focus on product development by CRIs has in many ways been the natural progression of these recent policies, and the development of pest and disease-resistant plant material has increased, in an effort to avoid a major mismatch between of capability and investment streams.

Furthermore, weed science in New Zealand remains in a very precarious state, with only a handful of active researchers left. A declining focus on production-based research is not helping what had already emerged as a critical situation. A reduction in graduates in weed science as well as other plant protection disciplines does not bode well, because without adequate recruitment and retention of appropriate expertise, New Zealand's base assets in primary resources and the natural estate will be the loser over time.

The currently reduced New Zealand emphasis on developing sustainable systems of pest, disease and weed management seems to be counter-trending with the rest of the world, in which most governments recognise and try to reduce huge losses in food and fibre production, estimated in some cases as high as $40 \%$ due to these sources. Integrated solutions will have the greatest and most long lasting success, and plant resistance needs to be supported by ecological knowledge and a range of other management tactics.

Company restructuring has also been occurring in a significant way, and nothing is more likely than further changes in the structure of local and multi-national companies in the plant protection business. The staff changes resulting from this regrouping, along with other commercial imperatives is placing increasing pressure on the size and extent of the agrichemical industry participation in the NZPPS. We must provide every opportunity to ensure that the declining number of personnel in this industry does not lessen their involvement.

The whole debate about genetic modification seems to me to be a parable about scientific literacy - in this case for a small country, unfortunately with a low level of real respect and appreciation for science and technology. It has been obvious that there has been a very sudden and relatively recent realisation by politicians and the public that food and environmental safety could be affected by a process which has been decades in development. This process concerns technology which is largely in the plant protection arena-principally with plants modified to carry Bt or herbicide expression. Yet how has it happened that the issues of what is now much wider debate have built up such a looming position of importance in the psyche of New Zealand? Part of the answer must lie in the area of scientific literacy. Perhaps this example can remind us that we need to invest strategically as a country in science, scientists and science communication - so

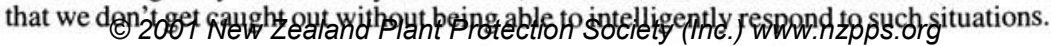


As an agnostic on the subject - I'm not saying that there are no risks - I'm just saying that as a country one can demonstrate a lack of appropriate investment in scientific literacy in this case. My concern is that this deficiency is at the infrastructural level and cannot be remedied quickly.

\section{So what is the role of the NZPPS in this environment ?}

The NZPPS has an important role in New Zealand society. We are an important forum for discussion and debate. As individuals or representatives of organisations, we may hold particular views on topics such as organics or genomics. However, as a Society affiliated to the Royal Society of New Zealand, we are advocates for scientificallybased debate and rational analysis. We can help to draw attention to issues which otherwise have a low profile, but which are strategically important.

With contributions like our recent "Managing Urban Weeds and Pests", the Society has continued to draw attention to pests and pest management, in this case using whatever pesticides and other tools are available in the human arsenal to manage our urban environment. The series of other publications we've produced from symposia during recent years has set us up with Manaaki Whenua Press as our marketing and distribution agent, and this relationship is working out well in our mutual interest.

Our web site is continuing to prove useful to members, carrying details of the updated instructions for authors and other timely information about the Conference. The search engine means that you can quickly find papers carrying keywords of interest for the last five years. The papers are then available on-line, which is state-of-the-art. The NZPPS is building an impressive and very functional web site.

The name change of the conference proceedings to "New Zealand Plant Protection" has been a positive step, which was not taken lightly. It has received a positive reception, and represents part of what we are trying to achieve through the strategic positioning of the Society as a premier source of high quality technical information.

The affiliation of the NZ Plant Protection Society with the International Association of Plant Protection Sciences (IAPPS) is also helping to boost international interest in what we have to offer. The IAPPS newsletter published monthly in the UK-based journal Crop Protection since January this year has already carried a country report for New Zealand, and carries our annual conference in the yearly diary, published each month in the back of the journal Crop Protection.

\section{So where will the future of plant protection lie in $\mathbf{2 0 0 0}$ and beyond ?}

The HSNO Act is providing plant protection with another set of challenges.

- The new rules for pesticide registration are raising the barriers for companies, and many are rethinking their strategies for the New Zealand market, increasingly from offices overseas.

- For people working on the introduction of biological control agents, the new legislation has much greater requirements for public consultation and hearings, and places the high costs of the new process on the applicants. The recent approval for the thrips biocontrol agent has set a positive precedent, but despite this signal, the process is very difficult, and the future of classical biological control in New Zealand remains uncertain.

- Can we expect plant protection solutions in New Zealand from the development and release of genetically modified organisms? The Royal Commission will obviously put the answer to that conundrum on hold for some time. The moratorium on further field trials will have an undeniable impact on science, as well as wider society. New Zealand society has a long way to go to develop a fuller debate on the potential for both organics and biotechnology.

- The rate of appearance of new threats to our biosecurity seems to have gone up dramatically recently. The statistics show how much our trade and tourism has increased, but they don't capture the long term economic cost of incursions, such as 
the Varoa mite with potential to impact significantly on pollination of a wide range of horticulture and seed crops. The application of traditional cost-benefit analysis to biosecurity threats seems likely to fail, given a time-line of "forever". How does a government decide what to eradicate and what to ignore, given this uncertainty? Relatively little research is being done in the area of biosecurity, yet the rational defense of our biological resources clearly demands a share of available funds.

Given the crudely estimated economic cost to New Zealand of pests, diseases and weeds, at $1 \%$ of GDP, the problems we work with are not going to go away, even if the resources to research and develop solutions become temporarily more scare. Such immense challenges will require people working in plant protection to be more innovative than ever. Our challenge will be to reach our potential to benefit New Zealand society at large in this difficult environment.

The $53^{\text {rd }}$ Conference was another highly successful meeting, with an excellent range of papers and posters. The New Zealand Plant Protection Society is a vibrant organisation with an excellent list of recent successes and a strong future. Your participation in the conference and wider events is a healthy sign. Let's face the challenges ahead with a positive attitude. 